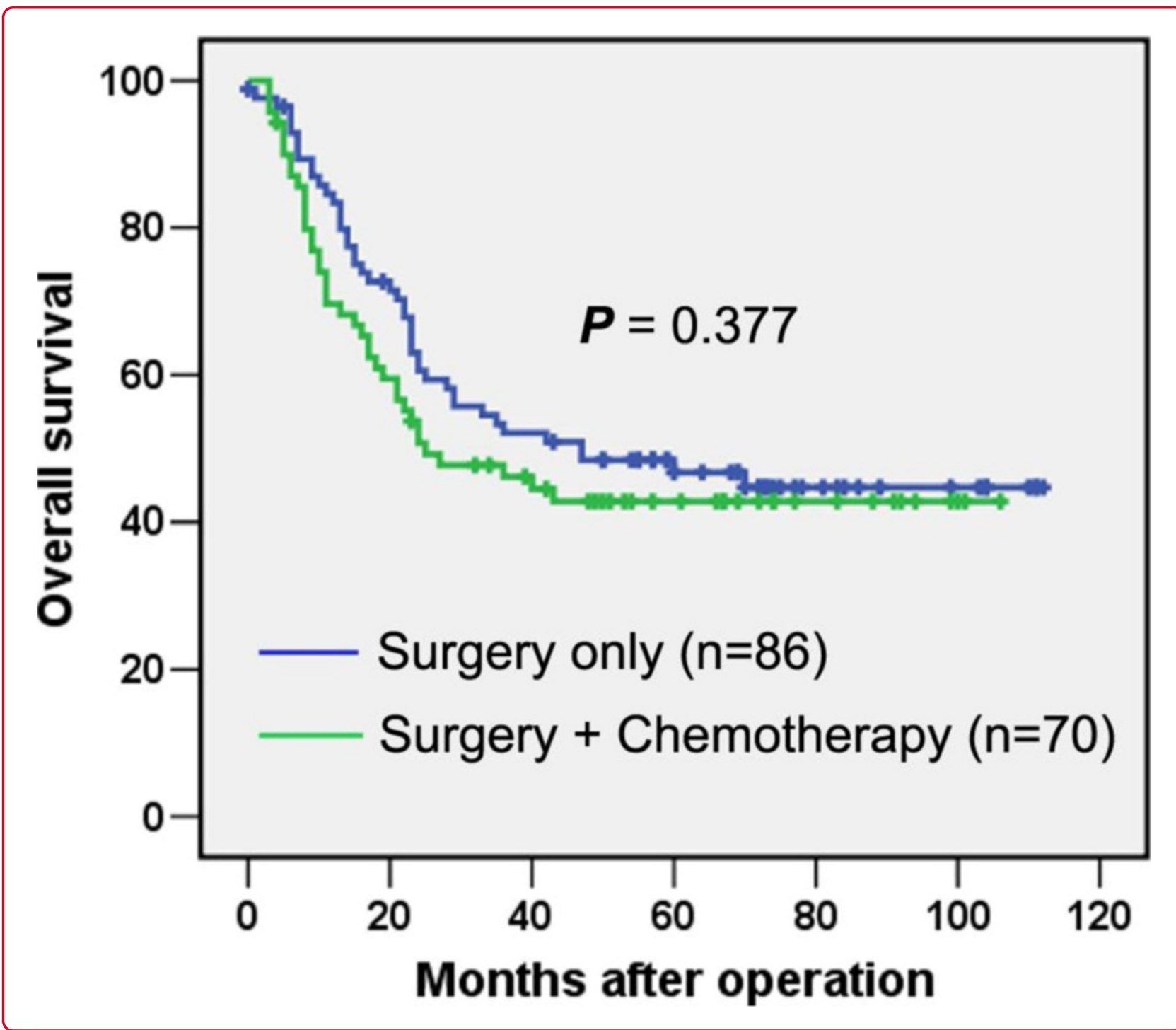

L1cam promotes tumor progression and metastasis and is an independent unfavorable prognostic factor in gastric cancer

Chen et al.

C Biomed Central 


\title{
L1cam promotes tumor progression and metastasis and is an independent unfavorable prognostic factor in gastric cancer
}

\author{
Dong-liang Chen ${ }^{1,2 \dagger}$, Zhao-lei Zeng ${ }^{1,3 \dagger}$, Jing Yang ${ }^{1,3}$, Chao Ren ${ }^{1,2}$, De-shen Wang ${ }^{1,2}$, Wen-jing Wu ${ }^{1,2}$ \\ and Rui-hua $\mathrm{Xu}^{1,2^{*}}$
}

\begin{abstract}
Background: Previous reports have demonstrated that L1cam is aberrantly expressed in various tumors. The potential role of L1 cam in the progression and metastasis of gastric cancer is still not clear and needs exploring.

Methods: Expression of L1cam was evaluated in gastric cancer tissues and cell lines by immunohistochemistry and Western blot. The relationship between L1cam expression and clinicopathological characteristics was analyzed. The effects of L1cam on cell proliferation, migration and invasion were investigated in gastric cancer cell lines both in vitro and in vivo. The impact of L1cam on PI3K/Akt pathway was also evaluated.

Results: L1 cam was overexpressed in gastric cancer tissues and cell lines. L1cam expression was correlated with aggressive tumor phenotype and poor overall survival in gastric cancer patients. Ectopic expression of L1cam in gastric cell lines significantly promoted cell proliferation, migration and invasion whereas knockdown of L1cam inhibited cell proliferation, migration and invasion in vitro as well as tumorigenesis and metastasis in vivo. The low level of phosphorylated Akt in HGC27 cells was up-regulated after ectopic expression of L1cam, whereas the high level of phosphorylated Akt in SGC7901 cells was suppressed by knockdown of L1cam. Moreover, the migration and invasion promoted by L1cam overexpression in gastric cancer cells could be abolished by either application of LY294002 (a phosphoinositide-3-kinase inhibitor) or knockdown of endogenous Akt by small interfering RNA.
\end{abstract}

Conclusions: Our study demonstrated that L1cam, overexpressed in gastric cancer and associated with poor prognosis, plays an important role in the progression and metastasis of gastric cancer.

Keywords: L1cam, Metastasis, PI3K/Akt, Prognosis, Gastric cancer

\section{Background}

Gastric cancer is the fourth most common malignancy and second leading cause of cancer-related mortality worldwide [1]. Although it is curable if detected early, most patients are diagnosed at advanced stage and have poor prognosis [2]. Tumor invasion and metastasis are critical steps in determining aggressive tumor phenotype and also constitute the main causes of cancer-related deaths [3]. Because traditional methods do not allow

\footnotetext{
* Correspondence: xurh@sysucc.org.cn

${ }^{\dagger}$ Equal contributors

'State Key Laboratory of Oncology in South China, Sun Yat-sen University Cancer Center, 651 Dong Feng East Load, Guangzhou 510060, China ${ }^{2}$ Department of Medical Oncology, Sun Yat-sen University Cancer Center, Guangzhou, China

Full list of author information is available at the end of the article
}

precise prediction of tumor progression and metastasis for patients after surgical resection of the primary tumor, there is an urgent need to identify new molecules that associated with gastric cancer progression and metastasis [4].

L1cam is a $220 \mathrm{kDa}$ multidomain type 1 membrane glycoprotein that belongs to the neuronal immunoglobulin superfamily of cell surface molecules [5]. L1cam contains six IgG-like and five fibronectin-type III domains in the extracellular region, a transmembrane region and a short intracellular cytoplasmic tail [6,7]. L1cam was first described as a neural cell adhesion molecule and has been shown to play an important role in cerebellar cell motility and development of the nervous system as well as neural growth and regeneration [8-10]. Besides neural cells, L1cam is found to be normally expressed in other

\section{Biomed Central}


cell types such as kidney tubule epithelial cells, intestinal crypt cells and myelomonocytic cells [11-13]. Recent reports found L1cam is also expressed in various tumor cells, including colorectal cancer, renal cell carcinoma, ovarian cancer, anaplastic thyroid carcinoma, malignant glioma, recurrent neuroblastoma and cutaneous malignant melanoma, and its expression is associated with tumor progression and invasion [14-20]. Studies have demonstrated that L1cam is able to stimulate many cellular activities via homophilic biding to the extracellular domains of the cells and heterophilic biding to other cell adhesion proteins, integrins, extracellular matrix molecules and cell surface receptors [21-23]. Ectopic expression of L1cam could promote tumor cell proliferation, migration and invasion in several types of cancer, including colon cancer, intrahepatic cholangiocarcinoma, and gallbladder carcinoma [24-26]. In gastric cancer, Kodera et al. reported L1cam was associated with prognosis of pT3-stage patients [27]. However, the biological role and underlying molecular mechanism of L1cam in gastric cancer progression and metastasis is still not known.

Akt (also known as Protein Kinase B) is a serine/threonine-specific protein kinase, which functions as a hub gene to integrate with different cellular signaling pathways [28]. Threonine 308 and serine 473 (two specific amino acid residues of Akt) can be phosphorylated upon full activation of Akt; Akt signaling has been shown to regulate multiple cellular activities, including cell cycle, cell growth, cell proliferation, cell migration/invasion and cell metabolism [29,30]. Activation of Akt signaling pathway has been found to be involved in tumor growth and invasion of some malignant disease $[15,25]$. However, it is still unknown whether L1cam can activate Akt and promote tumor growth and metastasis in gastric cancer.

In this study, we found L1cam was overexpressed in gastric cancer tissues and cell lines. Expression of L1cam was associated with clinicopathological characteristics and prognosis in gastric cancer patients. Knockdown of L1cam in gastric cancer cell lines significantly reduced cell proliferation, migration and invasion in vitro and suppressed tumorigenesis and metastasis in an experimental nude mouse model. Conversely, ectopic expression of L1cam in gastric cells significantly promoted these activities. Moreover, we found that the PI3K/Akt pathway was involved in the L1cam promoted cell proliferation, migration and invasion. These results suggest L1cam plays an important role in the progression and metastasis of gastric cancer and could be used as a new therapeutic target.

\section{Results}

L1cam is overexpressed in gastric cancer cell lines and tissues

L1cam mRNA expression was higher in all five gastric cancer cell lines compared with normal gastric cancer mucosa (Figure 1A). Western blot analysis confirmed overexpression of L1cam in all gastric cancer cell lines (Figure 1B). In matched primary gastric cancer tissues and adjacent normal tissues, the expression of L1cam mRNA was up-regulated by more than 1.5 fold in 19 of 30 (63\%) cancer tissues than that of normal tissues (Figure 1C). Western blot showed overexpression of L1cam in 23 of 30 (76\%) cancer tissues compared with adjacent normal tissues (Figure 1D).

\section{Overexpression of L1cam is associated with poor prognosis in gastric cancer}

To evaluate the clinicopathological significance of L1cam in gastric cancer, immunohistochemistry analysis was performed in 156 gastric cancer samples. As shown in Figure 2A, L1cam protein was mainly located in the cytoplasm and cell membrane of tumor cells. Positive staining was observed in 114 of 156 (73\%) cases. The patients were divided into the L1cam low expression group $(\mathrm{n}=85)$ and the L1cam high expression group $(\mathrm{n}=71)$ based on IHC scores. The correlation between L1cam expression and clinicopathological characteristics was listed in Table 1. High expression of L1cam was positively associated with large tumor size $(P=0.001)$, lymph node invasion $(P=0.007)$, peritoneal dissemination $(P=0.019)$, liver metastasis $(P=0.013)$ and TNM stage $(P=0.002)$. Kaplan-Meier analysis with log-rank test was performed to assess the prognostic significance of L1cam in gastric cancer. A significant difference of overall survival was found between patients with high L1cam expression and patients with low L1cam expression. Kaplan-Meier survival curves showed high L1cam expression was associated with poor overall survival $(P<0.001$, Figure 2B-D, Table 1$)$. Univariate analysis demonstrated patients with high L1cam expression tended to have a higher risk of death (HR $=2.73,95 \% \mathrm{CI}, 1.76-4.25 ; P<0.001$, Table 2). In addition, other parameters including tumor size, lymph node invasion and TNM stage were proved to be associated with overall survival as indicated by univariate analysis (Table 2). However, age, gender, differentiation status and therapeutic strategy had no prognostic significance in this studied population (Table 2, Additional file 1: Figure S1). Multivariate analysis showed only L1cam expression was an independent prognostic factors for gastric cancer patients $(P=0.022$, Table 2$)$.

\section{L1 cam promotes gastric cancer cell proliferation, migration and invasion in vitro}

Based on the data listed above, we further evaluated the role of L1cam in cell proliferation, migration and invasion. The HGC27 cell line, which had relative low expression of L1cam, was transfected with a pcDNA3.1(+)-L1cam plasmid to overexpress L1cam. Another gastric cancer cell line SGC7901 that expressed relative high level of 


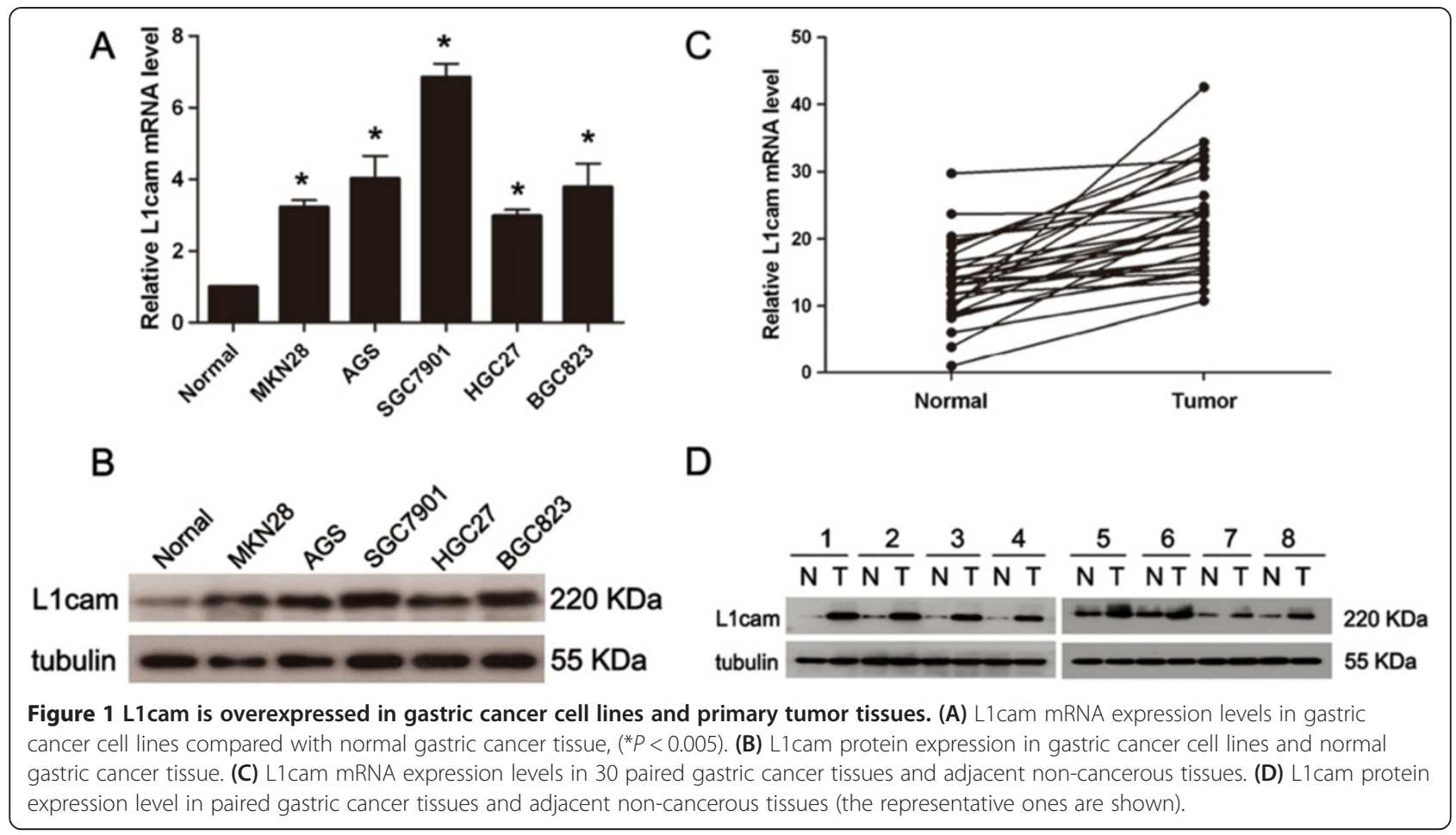

L1cam was treated with lentivirus that expressing short hairpin RNAs (shRNA) targeting L1cam to knockdown endogenous L1cam expression. The effect of ectopic expression and knockdown of L1cam in cells was confirmed by Western blot (Figure 3A). MTT assay showed that ectopic expression of L1cam could significantly promote the proliferative ability in HGC27 cells as compared with control cells $(P<0.05$, Figure 3B). Similarly, colony formation capacity was increased after overexpression of L1cam $(P<0.05$, Figure 3C). Conversely, knockdown of L1cam inhibited growth capacity in SGC7901 cells as indicated by the MTT and colony formation assays $(P<0.05$, Figure 3B and $\mathrm{C}$ ). Cell motility was measured by the migration and invasion assay. Compared with that of control cells, the migration and invasion ability were markedly stimulated in HGC27 cells that overexpressing L1cam $(P<0.05$, Figure 3D and E). Likewise, Knockdown of L1cam could apparently repress the migration and invasion of SGC7901 cells $(P<0.05$, Figure $3 \mathrm{D}$ and $\mathrm{E})$.

\section{L1 cam affects the responsiveness to oxaliplatin in gastric cancer cells}

In order to determine if L1cam could affect apoptosis and the responsiveness to anti-cancer drugs in gastric cancer cells, firstly, we analyzed the effect of L1cam on the apoptosis of gastric cancer cells, the results showed that overexpression or knockdown of L1cam had no significant effect on the apoptosis rate in gastric cancer cells (Figure 4A and B); then cells were treated with different concentrations of oxaliplatin, the results showed that knockdown of L1cam could improve the responsiveness to oxaliplatin in SGC7901 cells while overexpression of L1cam could reduce the apoptosis rate in HGC27 cells $(P<0.05$, Figure $4 \mathrm{~A}$ and $\mathrm{B})$.

\section{L1cam promotes tumorigenesis and metastasis of gastric} cancer cells in vivo

To analyze the in vivo effects of L1cam on gastric cancer cells, we constructed two stable cell lines by using the lentivirus vector to mediate the knockdown of L1cam in SGC7901 cells; the resulting cells were designated as SGC7901/scramble and SGC7901/sh-L1cam cells respectively.

These two cell lines were injected into the left and right flanks of each nude mouse respectively. Tumor size was measured over time; after five weeks, mice were sacrificed and tumors were dissected out. The results showed that tumor growth was significantly inhibited in SGC7901/sh-L1cam cells as compared with that of SGC7901/scramble cells $(P<0.05$, Figure 5A). In addition to the difference in tumor volume, we also found tumor tissues formed by injection of SGC7901/scramble cells displayed much stronger staining of L1cam and Ki-67, as detected by immunohistochemical analysis (Figure 5B). To explore the effect of L1cam on in vivo tumor metastasis, the two cell lines were injected into the tail vein of nude mice. Six weeks later, mice were sacrificed and lung and 


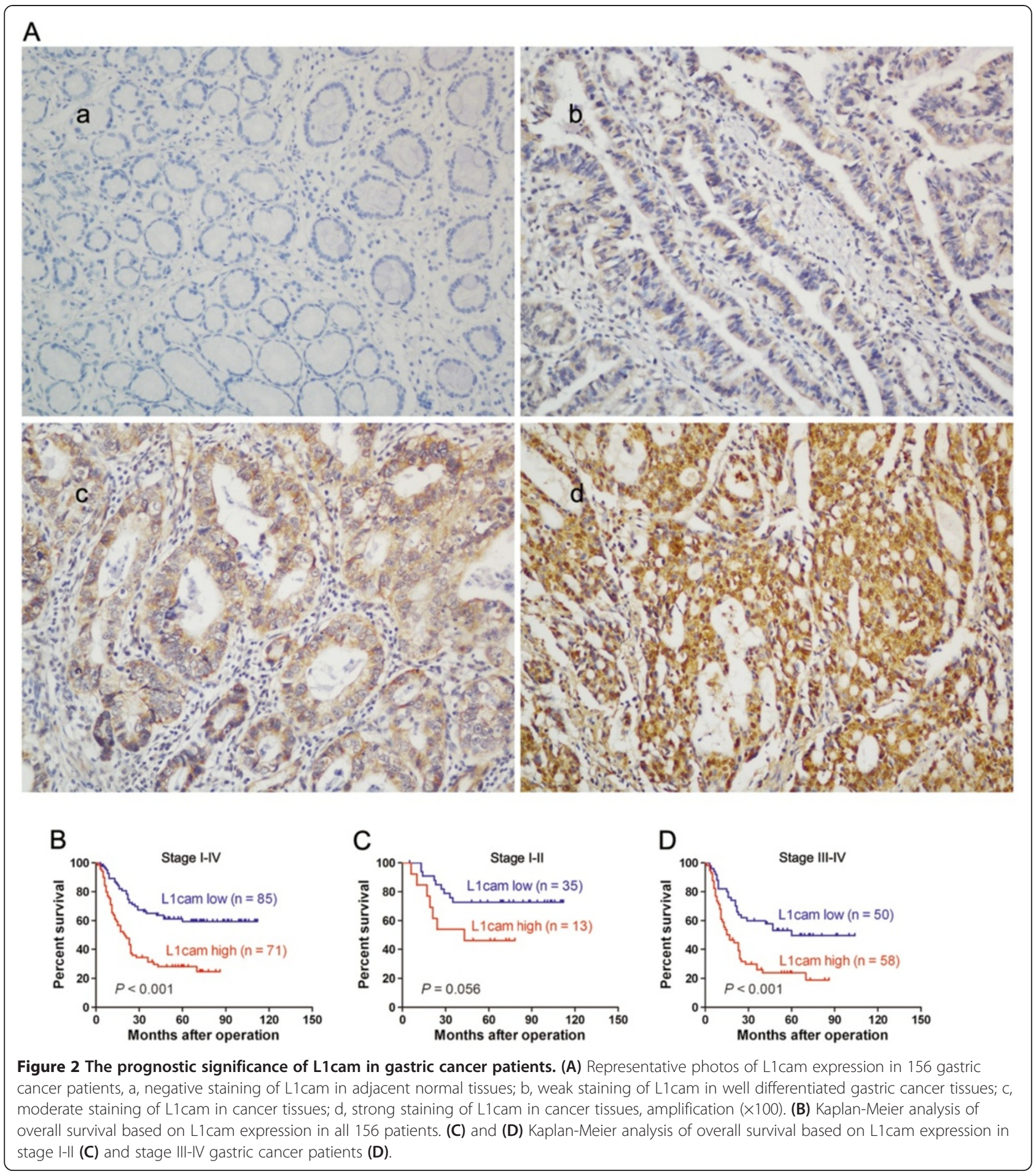

liver metastases were examined. Consistent with the in vitro results, the incidences of metastasis to lung and liver were significantly less in mice injected with SGC7901/ sh-L1cam cells than those of SGC7901/scramble cells $(P<0.05$, Figure $5 \mathrm{C})$. These data suggest knockdown of L1cam could also inhibit the tumor growth and metastasis of gastric cancer cells in vivo.
PI3K/Akt signal pathway is involved in L1cam mediated cellular activity

Relative high expression of L1cam was found in SGC7901 and AGS cells. Knockdown of L1cam dramatically decreased total phosphorylated Akt but not total Akt in SGC7901 and AGS cells (Figure 6A). Ectopic expression of L1cam in HGC27 and MKN28 cells significantly increased 
Table 1 Correlations between L1cam expression and clinicopathological characteristics in gastric cancer patients

\begin{tabular}{|c|c|c|c|c|}
\hline \multirow{3}{*}{ Characteristics } & \multirow{3}{*}{$\begin{array}{l}\text { Total } \\
\text { no. }\end{array}$} & \multicolumn{2}{|c|}{ L1cam expression } & \multirow{3}{*}{$P$ value } \\
\hline & & Low & High & \\
\hline & & $\begin{array}{l}\text { No. cases } \\
\text { (\%) }\end{array}$ & $\begin{array}{l}\text { No. cases } \\
\text { (\%) }\end{array}$ & \\
\hline
\end{tabular}

\begin{tabular}{|c|c|c|c|c|}
\hline Age & & & & 0.169 \\
\hline$<60$ & 97 & $57(67)$ & $40(56)$ & \\
\hline$\geq 60$ & 59 & 28(33) & $31(44)$ & \\
\hline Gender & & & & 0.342 \\
\hline Male & 106 & $55(64)$ & $51(72)$ & \\
\hline Female & 50 & $30(36)$ & 20(28) & \\
\hline Tumor size & & & & $0.001^{a}$ \\
\hline$<5 \mathrm{~cm}$ & 101 & $65(76)$ & $36(51)$ & \\
\hline$\geq 5 \mathrm{~cm}$ & 55 & $20(24)$ & $35(49)$ & \\
\hline Differentiation status & & & & 0.290 \\
\hline Well & 9 & $7(8)$ & 2(3) & \\
\hline Moderate & 87 & $48(56)$ & $39(55)$ & \\
\hline Poor and others & 60 & $30(36)$ & $30(42)$ & \\
\hline Lymph node invasion & & & & $0.007^{\mathrm{a}}$ \\
\hline Absent & 69 & $46(54)$ & $23(32)$ & \\
\hline Present & 87 & $39(46)$ & $48(68)$ & \\
\hline Venous invasion & & & & 0.077 \\
\hline Absent & 91 & $55(65)$ & $36(51)$ & \\
\hline Present & 65 & $30(35)$ & $35(49)$ & \\
\hline Peritoneal dissemination & & & & $0.019^{a}$ \\
\hline Absent & 123 & $73(86)$ & $50(70)$ & \\
\hline Present & 33 & $12(14)$ & $21(30)$ & \\
\hline Liver metastasis & & & & $0.013^{\mathrm{a}}$ \\
\hline Absent & 114 & $69(81)$ & $45(63)$ & \\
\hline Present & 42 & 16(19) & $26(37)$ & \\
\hline TNM $^{b}$ stage & & & & $0.002^{\mathrm{a}}$ \\
\hline$|-| \mid$ & 48 & $35(41)$ & 13(18) & \\
\hline III-IV & 108 & $50(59)$ & $58(82)$ & \\
\hline Therapeutic strategy & & & & 0.489 \\
\hline Surgery only & 86 & $49(58)$ & $37(52)$ & \\
\hline Surgery + Chemotherapy & 70 & $36(42)$ & $34(48)$ & \\
\hline Survival status & & & & $<0.001^{\circ}$ \\
\hline Alive & 72 & $52(61)$ & $20(28)$ & \\
\hline Dead & 84 & 33(39) & $51(72)$ & \\
\hline
\end{tabular}

${ }^{\mathrm{a}} P<0.05$, Chi-square test

${ }^{\mathrm{b}}$ TNM, T, tumor; N, lymph node; $\mathrm{M}$, distant metastasis.

phospho-Akt and slightly increased total Akt levels (Figure 6A); this effect could be abolished upon treatment of the phosphoinositide-3-kinase inhibitor LY294002 (Figure 6B). In addition, the stimulation of cell migration and invasion caused by ectopic expression of L1cam could also be suppressed by LY294002 administration (Figure 6C). Similarly, the up-regulation of total Akt and phospho-Akt caused by ectopic expression of L1cam in HGC27 cells could be counteracted by knockdown of Akt using siRNA (Figure 6D); the effect on cellular motility caused by L1cam overexpression was also inhibited upon silencing of Akt (Figure 6E). Moreover, treatment of LY294002 in SGC7901 cells could significantly inhibit tumor growth in nude mice (Figure 6F), and the expression of phospho-Akt was reduced in tissues formed by cells that knockdown of L1cam or treated with LY294002 (Figure 6G). These results demonstrated that PI3K/Akt signaling was involved in L1cam stimulated cell growth and motility in gastric cancer cells.

\section{Discussion}

In this study, we found that both L1cam mRNA and protein level was increased in gastric cancer cells and tissues. L1cam was detected in $73 \%$ of the tissues from gastric cancer patients by using IHC. Previously, Kodera et al. reported that L1cam was expressed in $21 \%$ of the specimens [27], but this study included p-T3 stage patients only, thus the inconsistency might be due to ethnic difference and difference in tumor stage. Moreover, expression of L1cam was significantly correlated with aggressive tumor characteristics (tumor size, lymph node invasion, peritoneal dissemination, liver metastasis and TNM stage) and poor prognosis; when the patients were subdivided into two groups according to tumor stage, we found L1cam could better distinguish patients with different outcomes in stage III-IV than in stage I-II patients, however, this might be due to the limited subjects in stage I-II. Multivariate analysis demonstrated that L1cam expression was an independent prognostic factor for gastric cancer patients. These observations suggested that overexpression of L1cam might be a common incidence in gastric cancer and could serve as an independent prognostic indicator to identify patients with different outcomes. In line with our study, up-regulation of L1cam was also found in other tumors, such as ovarian cancer, colorectal cancer, anaplastic thyroid carcinoma and intrahepatic cholangiocarcinoma $[14,16,17,25]$. However, further study is needed to confirm if L1cam could be used as a universal biomarker of prognosis for neoplasm.

As L1cam expression was associated with aggressive tumor phenotype in gastric cancer, we speculated that L1cam might play an important role in tumor biology. Indeed, knockdown of endogenous L1cam expression significantly inhibited cell proliferation, migration and invasion, whereas ectopic expression of L1cam enhanced these capacities. This is in line with previous studies that highlighted the role of L1cam in progression and metastasis of a variety of tumor types, such as uterine and ovarian carcinoma, human malignant melanoma, 
Table 2 Univariate and multivariate analysis of various potential prognostic factors in gastric cancer patients

\begin{tabular}{|c|c|c|c|c|c|}
\hline \multirow[t]{2}{*}{ Factors } & \multicolumn{3}{|c|}{ Univariate analysis } & \multicolumn{2}{|c|}{ Multivariate analysis } \\
\hline & Case NO. & $\mathrm{HR}^{\mathrm{b}}\left(95 \% \mathrm{Cl}^{\mathrm{c}}\right)$ & $P$ & $\mathrm{HR}^{\mathrm{b}}\left(95 \% \mathrm{Cl}^{\mathrm{c}}\right)$ & $P$ \\
\hline Age $(<60 / \geq 60)$ & $87 / 69$ & $0.94(0.61-1.44)$ & 0.785 & - & - \\
\hline Gender (male/female) & $106 / 50$ & $1.17(0.74-1.84)$ & 0.511 & - & - \\
\hline Differentiation (well, moderate/poor) & $77 / 79$ & $0.79(0.46-1.74)$ & 0.381 & - & - \\
\hline Therapeutic strategy ${ }^{\mathrm{d}}$ (Sur/Sur + Chemo) & $86 / 70$ & $1.21(0.79-1.86)$ & 0.377 & - & - \\
\hline Tumor size $(\geq 5 \mathrm{~cm} /<5 \mathrm{~cm})$ & $105 / 51$ & $2.27(1.54-3.37)$ & $0.001^{\mathrm{a}}$ & $1.73(0.99-3.03)$ & 0.055 \\
\hline Lymph node invasion (present/absent) & $111 / 45$ & $1.55(1.25-1.92)$ & $0.012^{\mathrm{a}}$ & 1.05(0.73-1.53) & 0.780 \\
\hline TNM stage (III-IV/I-II) & $108 / 48$ & $1.95(1.48-2.55)$ & $0.001^{\mathrm{a}}$ & $1.36(0.81-2.31)$ & 0.249 \\
\hline L1cam expression (high/low) & $71 / 85$ & $2.73(1.76-4.25)$ & $<0.001^{\mathrm{a}}$ & $1.94(1.27-4.31)$ & $0.022^{\mathrm{a}}$ \\
\hline
\end{tabular}

glioma and colorectal cancer [31-36]. It has been reported that L1cam could bind to a variety of integrins, form a protein-protein complex and activate several signaling pathways to promote cell adhesion and motility [37]; these L1cam/integrin-mediated signaling transduction may also integrate with growth factor signaling networks to stimulate cellular motility [37]. In addition, L1cam enables endocytosis of integrins by tumor cells, thus reducing cell adhesion to the extracellular matrix and promoting cell migration [38]. In the present study, in order to see whether L1cam can interact with integrins to promote cell motility in gastric cancer cells, SGC7901 cells as well as HGC27 cells overexpressing L1cam were treated with siRNAs against integrins ( $\beta 1, \alpha 5 \beta 1, \alpha \mathrm{v} \beta 3$ and $\alpha \mathrm{v} \beta 5$ integrins) that have been reported to be involved in L1cam mediated cellular activities. However, no significant effect on cellular proliferation and invasion was observed upon administration of these siRNAs. This is different from the results in some other tumors, for example, L1cam stimulated cell invasion by regulating FAK activation, possibly through interaction with integrin receptors after ADAM10 shedding in human glioma [39]; likewise, integrins are essential for L1cam-mediated NF-kappaB activation and cellular motility and invasiveness in pancreatic adenocarcinoma and breast cancer cells [40,41]. However, further study is needed to investigate the interaction of L1cam and integrins in gastric cancer cells.

Given that L1cam can promote gastric cancer cell proliferation, migration and invasion in vitro, we further investigated the in vivo effect of L1cam. To our interest, knockdown of L1cam by lentiviral-mediated short hairpin RNA (shRNA) interference significantly suppressed tumor growth and distant metastasis to lung and liver. This is in line with previous study that targeting L1cam decreased tumor growth and increased tumor-bearing survival in glioma and Cholangiocarcinoma [25,42]. Besides, L1cam monoclonal antibodies have been shown to reduce in vivo tumor growth of several types of cancer cells in mouse xenograft models, including ovarian cancer, colon carcinoma and intrahepatic Cholangiocarcinoma [25,43-45]. In this study, we also found that L1cam could affect the responsiveness to oxaliplatin in gastric cancer cells. In line with our results, it has been found that L1cam conferred anti-apoptotic protection and chemoresistance in pancreatic ductal adenocarcinoma cells [46]; moreover, a recent study demonstrated that inhibiting L1cam by using L1cam antibodies could increase the apoptotic response of tumor cells towards cytostatic drugs in pancreatic and ovarian carcinoma [47]. These results raise the possibility that L1cam could be used as a therapeutic target and L1cam antibodies might serve as chemosensitizers for malignant disease, including gastric cancer.

Recent studies have revealed that L1cam is involved in several signal pathways. For example, the Wnt/ $\beta$-catenin/TCF pathway was found to induce the expression of L1cam in advanced colon cancer [36]. Ectopic expression of L1cam in ovarian carcinoma cells activates Erk and FAK signal pathways to promote cellular migration, invasion and apoptosis resistance $[48,49]$. In human glioma, L1cam stimulated cell motility via binding to integrin receptors, activating FAK, and increasing turnover of focal complexes [39]. L1cam could enhance cell proliferation by mainly activating ERK signaling in intrahepatic cholangiocarcinoma cells [50]. In the present study, we found ectopic expression in HGC27 cells activated PI3K/Akt signaling whereas knockdown of L1cam in SGC7901 cells inhibited Akt signaling. In addition, the increased cellular motilities promoted by L1cam could be eliminated by blocking of PI3K/Akt pathway in gastric cancer cells. Similar to our results, Min et al. reported Akt signaling is 


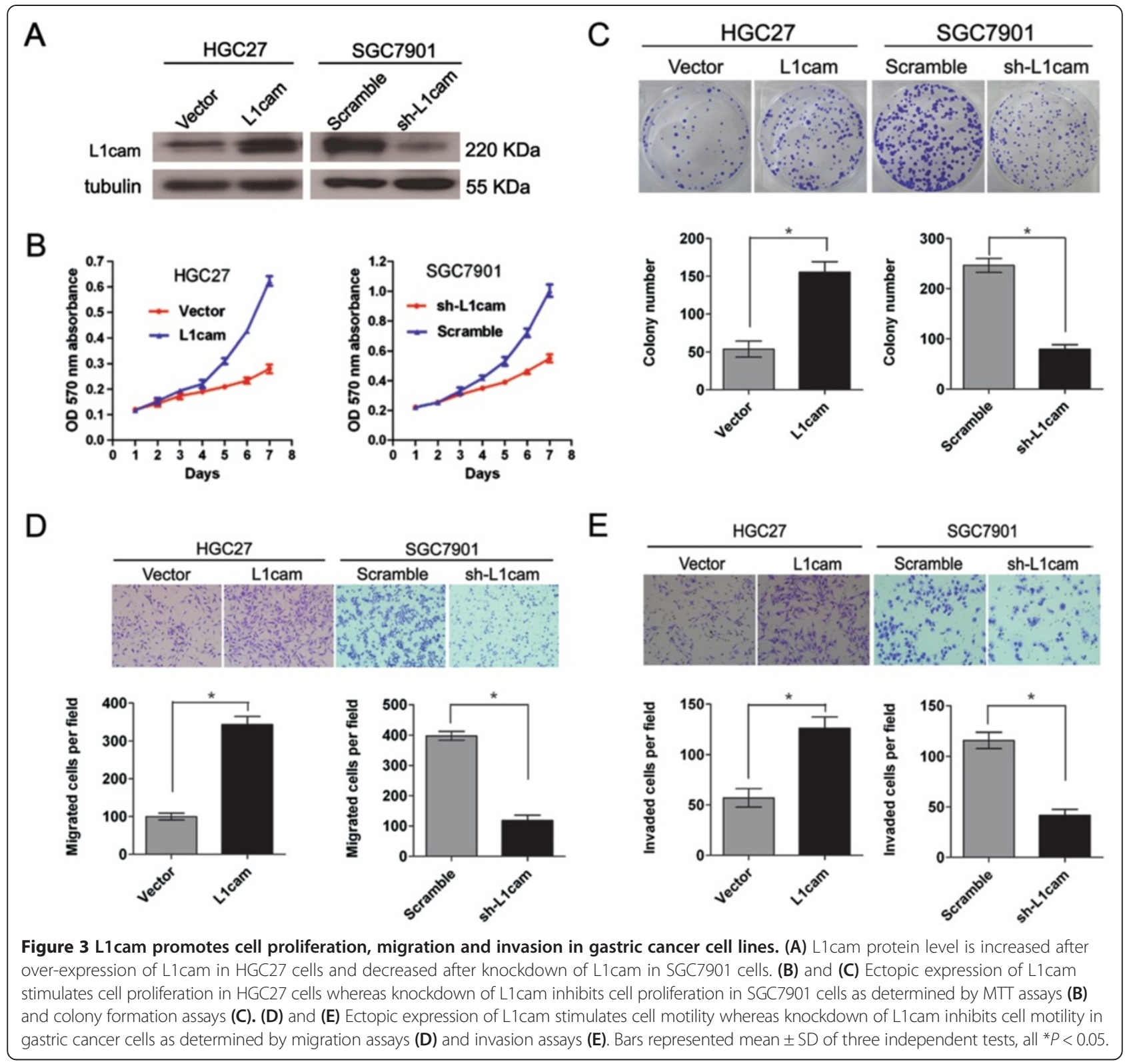

responsible for L1cam stimulation of intrahepatic cholangiocarcinoma progression [25]; Doberstein et al. found that L1cam could activate P13K/Akt pathway to induce cell proliferation and invasion in renal cell carcinoma [15]. These results suggest that the signaling pathways activated by L1cam may be tumor specific. However, further investigation is needed to explore the underlying molecular mechanism by which L1cam promotes gastric cancer progression and metastasis.

\section{Conclusions}

In the present study, we found L1cam is overexpressed in gastric cancer cells and tissues. L1cam expression is associated with aggressive tumor phenotypes and poor survival in gastric cancer patients. Overexpression of L1cam promotes cell proliferation, migration and invasion, chemoresistanse as well as tumorigenesis and metastasis via activation of PI3K/Akt signaling pathway in gastric cancer. Therefore, L1cam expression level could be used for prediction of cancer progression, metastasis and prognosis of gastric cancer patients. Targeting L1cam might be a promising therapeutic strategy for gastric cancer patients.

\section{Materials and methods}

Human tissue specimens and cell lines

A cohort of 156 formalin-fixed, paraffin-embedded tissue samples collected from gastric cancer patients who 

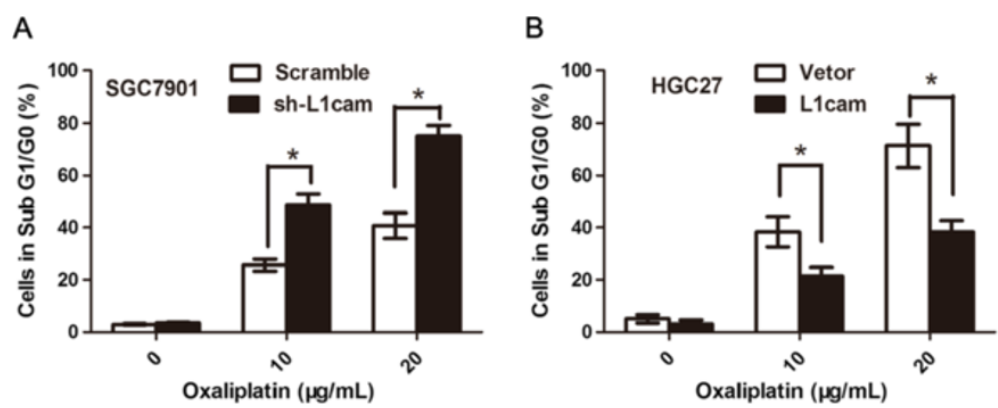

Figure 4 L1cam affects the reponsiveness to oxaliplatin of gastric cancer cells. (A) SGC7901 cells were transfected with sh-L1cam or sramble lentivirus. Cells were left untreated or administrated with different concentrations of oxaliplatin and cell cycle analyses were performed. Graph indicates the percentage of cells in sub G1/GO phase (apoptotic cells), * $P<0.05$. (B) HGC27 cells were transfected with L1cam or negative control vectors. Cells were left untreated or administrated with different concentrations of oxaliplatin and cell cycle analyses were performed. Graph indicates the percentage of cells in sub G1/G0 phase (apoptotic cells), *P $<0.05$.

underwent surgery in Sun Yat-sen University Cancer Center (Guangzhou, China) between 2004 and 2006 were retrieved. Fresh gastric cancer tissues and matched adjacent noncancerous tissues were obtained from 30 of the 156 patients and stored in liquid nitrogen until use. All the patients had a histological diagnosis of gastric cancer. A written informed consent was obtained from each patient involved in this study and the study protocol was approved by the ethics committee of Sun Yat-sen University Cancer Center. All the patients underwent total or subtotal gastrectomy, none of the patients received any treatment before surgery. Seventy patients who received adjuvant chemotherapy after surgery were on the 5-FU, platinum or taxol-based regimens. Each patient was followed-up regularly after operation at three-month interval. The median follow-up time was 30 months (range: 3 to 112 months). All the clinicopathological information including age, gender, tumor size, differentiation status, lymph node invasion, venous invasion, peritoneal dissemination, liver metastasis and TNM stage were retrieved from patients' medical records.

Five human gastric cancer cell lines (MKN28, AGS, SGC7901, HGC27 and BGC823) were obtained from either the American Type Culture Collection or RIKEN Cell Bank; cells were cultured and stored according to providers' instructions. Cells were routinely authenticated every six months (last examined in September 2012) by growth curve analysis, cell morphology monitoring and testing for mycoplasma.

\section{RNA isolation and real-time quantitative RT-PCR analysis}

Total RNA was extracted from the tissues and cells with Trizol reagent (Invitrogen) according to the manufacturer's instructions. The details for reverse transcription of RNA and real-time PCR are described previously [51]. L1cam mRNA expression were measured using a SYBR Premix Ex Taq ${ }^{\text {Tw }}$ kit (Takara); $\beta$-actin expression was used as a reference. The PCR primers for amplifications for L1cam and $\beta$-actin were:

L1cam forward: 5'-GACTACGAGATCCACTTGTTT AAGGA-3';

L1cam reverse: 5' -CTCACAAAGCCGATGAACCA-3'; $\beta$-actin forward: 5'-TGGATCAGCAAGCAGGAGTA-3'; $\beta$-actin reverse: $5^{\prime}$-TCGGCCACATTGTGAACTTT-3'. Real-time PCR was carried out with an ABI PRISM ${ }^{\circ}$ 7500 Seqtence Detection System. The relative level of L1cam mRNA was normalized to that of $\beta$-actin and calculated by the $2^{-\Delta \Delta c t}$ method.

\section{Western blot analysis}

Western blot analysis was performed according to a standard method as described previously [52]. For immunoblotting of L1cam, a mouse L1cam antibody (sc-33686) was purchased from Santa Cruz Biotechnology. For detection of Akt and p-Akt, rabbit antibodies against total Akt and Ser $^{473}$ phosphorylated Akt were obtained from Cell Signaling Technology. A mouse monoclonal $\alpha$-tubulin antibody (1:20000; Abcam) was used as loading control.

\section{Immunohistochemistry (IHC) analysis}

The paraffin-embedded tissue blocks were cut into $4 \mu \mathrm{m}$ slides. A mouse L1cam antibody (sc-33686) was used for immunostaining. IHC analysis of L1cam was performed according to a previously described method [53]. To quantify L1cam protein expression, both the intensity and extent of immunoreactivity were evaluated and scored. In the present study, IHC intensity was scored as follows: 0 , negative staining; 1 , weak staining; 2 , moderate staining; 3 , strong staining. The scores of the extent of immunoreactivity ranged from 0 to 3 and were according to the percentage of cells that had positive staining in each microscopic field of view $(0,<25 \% ; 1,25 \%-50 \%$; $2,50 \%-75 \% ; 3,75 \%-100 \%)$. A final score ranging from 


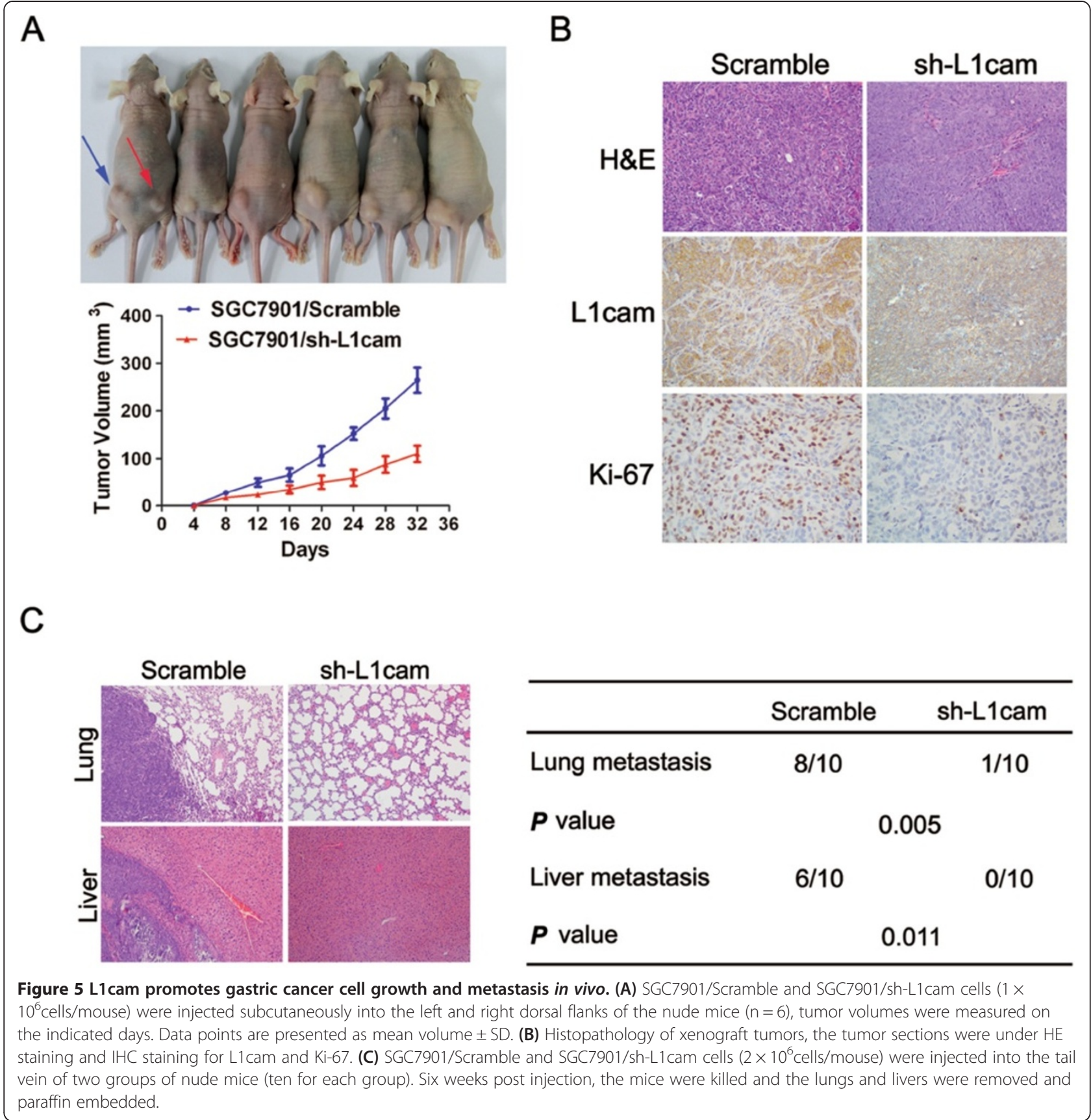

0 to 9 was achieved by multiplying the scores for intensity and extent. L1cam expression level was considered high when the final scores were $\geq 4$ and low when the final scores were $<4$.

\section{Vector construction and transfection, lentivirus production and transduction}

To overexpress L1cam, the coding sequence of L1cam was amplified and subcloned into the pcDNA3.1 (+) vector (Invitrogen, CA, USA) according to the manufacturer' instructions. HGC27 cells were then transfected with a negative control vector or L1cam expressing plasmid using lipofectamine 2000 (Invitrogen). The resultant cells were named HGC27/Vector and HGC27/L1cam cells, respectively. To generate L1cam stable knockdown cells, lentivirus containing L1cam short hairpin RNA (shRNA) or scrambled oligonucleotides were obtained from GenePharma Biotech (Shanghai, China). An annealed short interfering RNA (siRNA) for L1cam selected from 3 different target sequences was inserted into the LV-3 (pGLVH1/GFP + Puro) vector. SGC7901 cells were transduced with lentivirus and stable cell lines were selected per 
A

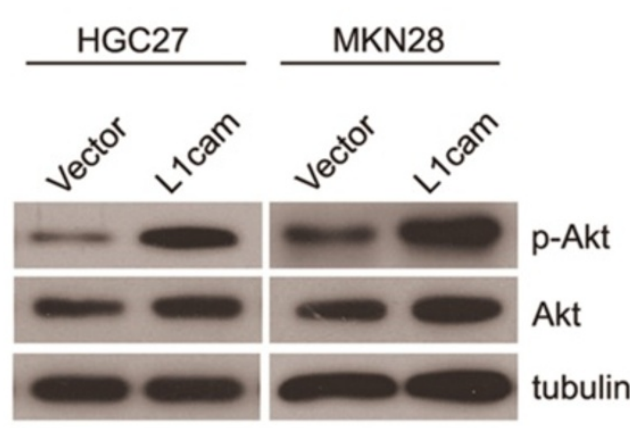

B

$$
\begin{aligned}
& ++-\quad-\text { Vector } \\
& -\quad++ \text { L1cam } \\
& +-+- \text { DMSO } \\
& -+-+ \text { LY294002 } \\
& -- \text { Akt } \\
& -\infty-\infty \text { tubulin }
\end{aligned}
$$

D

$$
\begin{aligned}
& ++-- \text { Vector } \\
& -+++ \text { L1cam } \\
& +-+- \text { Scramble } \\
& ++-+ \text { si-Akt } \\
& -\infty \text { p-Akt } \\
& --\infty-\text { Akt } \\
& \infty+\infty \text { tubulin }
\end{aligned}
$$

$\mathrm{F}$

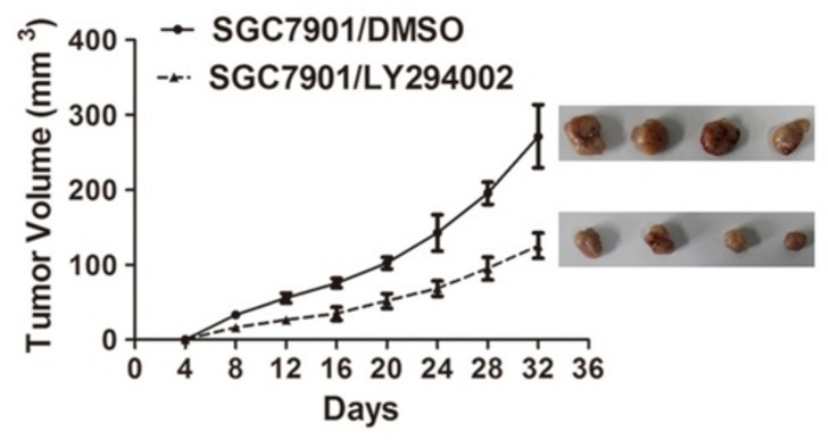

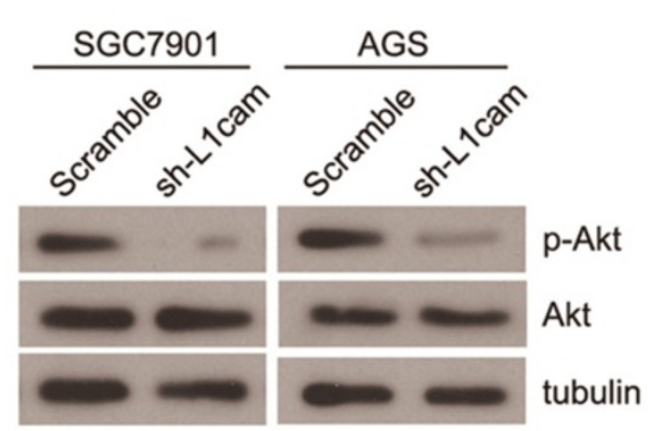

C

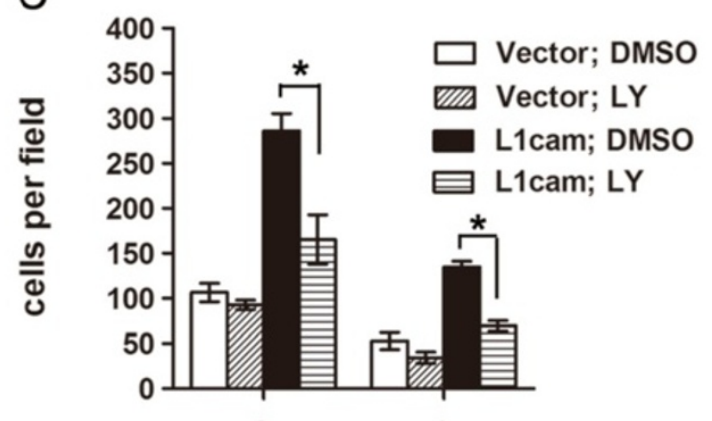

E

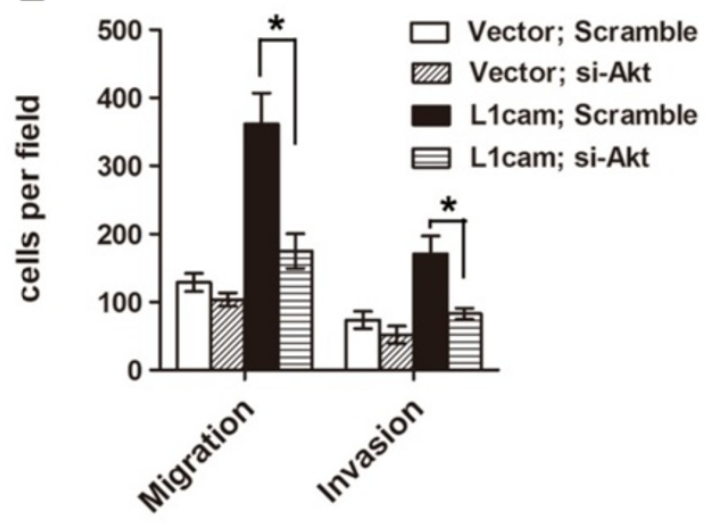

G

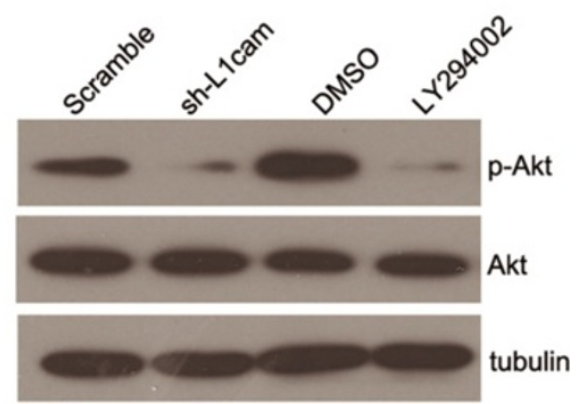

Figure 6 (See legend on next page.) 


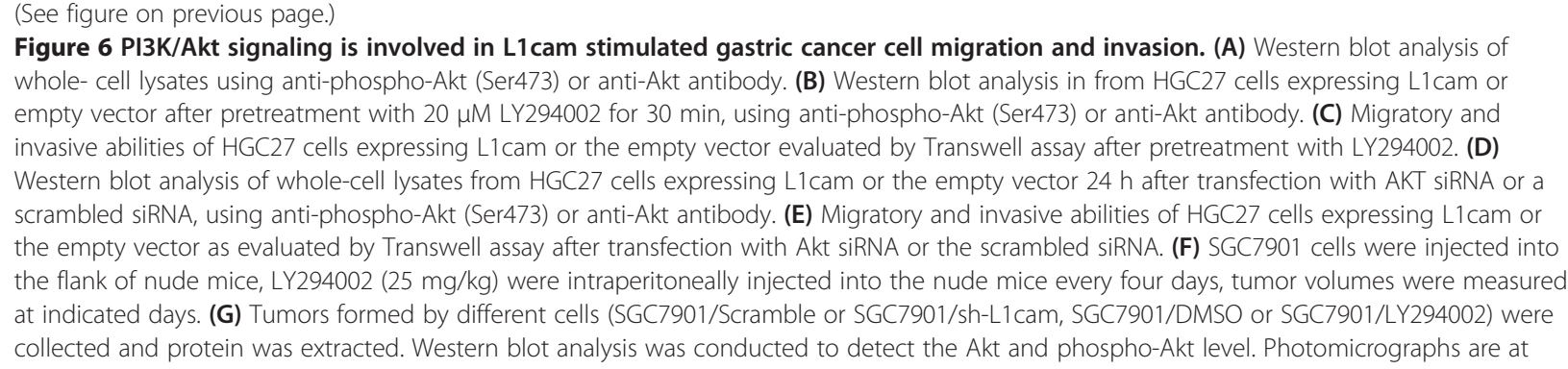

the manufacturer's instructions. The targets for L1cam shRNA were, for sh-L1cam\#1, 5'-GGAAATGAGACC ACCAATA-3'; for sh-L1cam\#2, 5'-CAACAGTGCTTCA GGACGA-3'; for sh-L1cam\#3, 5'-CGATGAAAGATGAG ACCTT-3'. In this study, we used sh-L1cam\#1 because it could effectively knockdown endogenous L1cam in gastric cancer cell lines based on our preliminary experiments. The target sequence for scrambled shRNA was $5^{\prime}$-GTCT CCACGCGCAGTACATTT-3'. The cell lines stably expressing L1cam shRNA or scrambled oligonucleotides were designated as SGC7901/sh-L1cam and SGC7901/ scramble cells, respectively.

\section{Cell proliferation assays}

The 3-(4, 5-dimethylthiazole-2-yl)-2, 5-biphenyl tetrazolium bromide (MTT) assay was performed to test cell viability and proliferation. The spectrophotometric absorbance at $570 \mathrm{~nm}$ was measured for each sample, all the experiments were repeated 3 times in triplicate and the mean was calculated.

For the colony formation assay, 500 cells were placed in a six-well plate and cultured for 14 days with RPMI 1640 medium (GIBCO) containing 10\% FBS. Colonies were fixed with methanol and stained with $0.1 \%$ crystal violet $(1 \mathrm{mg} / \mathrm{ml})$.

\section{In vitro invasion and migration assay}

The cell invasive and migratory potential was evaluated using transwell chambers ( $8 \mu \mathrm{m}$ pore; BD Biosciences). For the invasion assay, $1 \times 10^{5}$ cells suspended in $100 \mu \mathrm{l}$ serum-free medium were added to the upper chamber of the inserts, which were coated with a mitrigel mix; fetal bovine serum $(500 \mu \mathrm{l})$ was added to the lower chamber as a chemoattractant. After incubation for 24 hours, non-invading cells on the upper surface were wiped off with a cotton swab and cells that invaded to the lower side of the membrane were fixed with methanol, stained with $0.1 \%$ crystal violet, air dried and photographed. For the migration assay, tumor cells $\left(5 \times 10^{4}\right.$ cells in $100 \mu \mathrm{l}$ serum-free medium) were placed in the top chamber of each insert without matrix gel, and $500 \mu \mathrm{l}$ fetal bovine serum was added to the lower compartment. 16 hours later, the cells on the upper side were removed, and the cells that migrated to the lower chamber were fixed and stained with crystal violet. The number of invading or migrating cells was determined by microscopically counting five different fields.

\section{Cell cycle analysis}

Cells were seeded in six-well plates and cultured for 12 hours, and then cells were left untreated or treated with different concentrations of oxaliplatin $(10 \mu \mathrm{g} / \mathrm{mL}$ or $20 \mu \mathrm{g} / \mathrm{mL}$ ) for 24 hours. Afterward, cells were collected and washed with phosphate-buffered saline, cell cycle analysis was carried out as previously described [54].

\section{In vivo proliferation and metastasis assays}

Female BABL/c athymic nude mice (four to five weeks old) were obtained from the Animal Center of Guangdong province (Guangzhou, China). All the animal experiments were performed according to the National Institutes of Health animal use guidelines on the use of experimental animals.

To evaluate the in vivo proliferative effect of L1cam, the SGC7901/Scramble and SGC7901/sh-L1cam cells $\left(1 \times 10^{6}\right.$ cells/mouse $)$ were injected subcutaneously into the left and right dorsal flanks of the nude mice. Tumor size was measured every four days and tumor volume was estimated. After five weeks, the mice were sacrificed and the tumors were dissected out. Tumor tissues were fixed with $10 \%$ formalin and embedded in paraffin. Representative tumor sections were obtained from paraffin-embedded tumor tissue and stained with haematoxylin-eosin (H\&E) or specific antibodies.

To investigate the effect of L1cam on tumor metastasis, the SGC7901/Scramble and SGC7901/sh-L1cam cells $\left(2 \times 10^{6}\right.$ cells/mouse) were injected into the tail vein of two groups of nude mice (ten for each cell group). Six weeks post injection, the mice were sacrificed and the lungs and livers were removed and paraffin embedded. Consecutive sections $(4 \mu \mathrm{m})$ were made and stained with haematoxylin-eosin. The micro-metastases in the lungs and livers were examined and counted under a dissecting microscope as described previously [55]. 


\section{Blocking of PI3K/Akt pathway and assays}

LY294002, a specific inhibitor of PI3K, was purchased from Cell Signaling Technology. For administration of LY294002, tumor cells were incubated with $50 \mu \mathrm{M}$ LY294002 (Cell Signaling Technology) for one hour before performing in vitro assays. Small-interfering RNA (siRNA) targeting Akt and a scrambled siRNA were purchased from Ribobio (Guangzhou, China). The target sequence for AKT siRNA is 5'-GCACCTTCATTGGC TACAA-3', and the target for scrambled siRNA is $5^{\prime}$ CGTACGCGGAATACTTCGA-3'. For siRNA transfection, cells were plated in a six-well plate the day before transfection. Twenty-four hours later, cells were transfected with $50 \mathrm{nM}$ siRNAs using lipofectamine 2000 (Invitrogen) according to the manufacturer's instructions. The efficiency of gene silencing was confirmed by immunoblotting. Migration and invasion assays were performed twenty-four hours after siRNA transfection in gastric cancer cells. To evaluate the in vivo effect of LY294002, SGC7901 cells were subcutaneously implanted into the flank of nude mice, Seven days later, LY294002 (25 mg/kg) were intraperitoneally injected into the nude mice every four days. The tumor volume was measured every four days. The mice were sacrificed after 5 weeks and the tumors were dissected out.

\section{Statistical analysis}

Statistical analysis was performed using the SPSS software package (version 16.0, SPSS Inc). Statistical significance was tested by a Student's t-test or a Chi-square test as appropriate. Survival analysis was performed using the Kaplan-Meier method, and the log-rank test was used to compare the differences between patient groups. Parameters with a $P$ value $<0.05$ by univariate analysis were subject to multivariate analysis using the Cox proportional hazards model to identify independent prognostic factors for gastric cancer patients. All differences were statistically significant with a value of $P<0.05$.

\section{Additional file}

Additional file 1: Figure S1. Kaplan-Meier analysis of overall survival based on Therapeutic strategies in 156 gastric cancer patients.

\section{Abbreviations}

IHC: Immunohistochemistry; TNM: Tumor, lymph node, distant metastasis; MTT: 3-(4, 5-dimethylthiazole-2-yl)-2, 5-biphenyl tetrazolium bromide; siRNA: Small interfering RNA.

\section{Competing interests}

The authors declare that they have no competing interests.

\section{Authors' contributions}

$\mathrm{CDL}$ conceived of the study, carried out the Western blotting analysis, $\mathrm{IHC}$ analysis, molecular studies and drafted the manuscript. ZZL performed the animal experiments. YJ and RC collected the clinical data. WDS and WWJ performed the statistical analysis. $\mathrm{XRH}$ participated in the design of the study and helped to draft the manuscript. All authors read and approved the final manuscript.

\section{Acknowledgements}

This study was supported by the grant from National High-tech R\&D Program (863 Program), China (No.2012AA02A506) and The Science and Technology Department of Guangdong Province, China (No. 2012B031800088)

\section{Author details}

${ }^{1}$ State Key Laboratory of Oncology in South China, Sun Yat-sen University Cancer Center, 651 Dong Feng East Load, Guangzhou 510060, China. ${ }^{2}$ Department of Medical Oncology, Sun Yat-sen University Cancer Center, Guangzhou, China. ${ }^{3}$ Department of Experimental Research, Sun Yat-sen University Cancer Center, Guangzhou, China.

Received: 13 March 2013 Accepted: 24 June 2013

Published: 27 June 2013

\section{References}

1. Jemal A, Siegel R, Xu J, Ward E: Cancer statistics, 2010. CA Cancer J Clin 2010, 60:277-300

2. Wang $X N$, Liang $H$ : Some problems in the surgical treatment of gastric cancer. Chin J Cancer 2010, 29:369-373.

3. Steeg PS: Metastasis suppressors alter the signal transduction of cancer cells. Nat Rev Cancer 2003, 3:55-63.

4. Hohenberger P, Gretschel S: Gastric cancer. Lancet 2003, 362:305-315.

5. Lindner J, Rathjen FG, Schachner M: L1 mono- and polyclonal antibodies modify cell migration in early postnatal mouse cerebellum. Nature 1983, 305:427-430.

6. Brummendorf T, Rathjen FG: Axonal glycoproteins with immunoglobulin- and fibronectin type III-related domains in vertebrates: structural features, binding activities, and signal transduction. J Neurochem 1993, 61:1207-1219.

7. Hortsch M: The L1 family of neural cell adhesion molecules: old proteins performing new tricks. Neuron 1996, 17:587-593.

8. Moos M, Tacke R, Scherer H, Teplow D, Fruh K, Schachner M: Neural adhesion molecule $\mathrm{L} 1$ as a member of the immunoglobulin superfamily with binding domains similar to fibronectin. Nature 1988, 334:701-703.

9. Rathjen FG, Schachner M: Immunocytological and biochemical characterization of a new neuronal cell surface component (L1 antigen) which is involved in cell adhesion. EMBO J 1984, 3:1-10.

10. Dahme M, Bartsch U, Martini R, Anliker B, Schachner M, Mantei N: Disruption of the mouse L1 gene leads to malformations of the nervous system. Nat Genet 1997, 17:346-349.

11. Debiec H, Christensen El, Ronco PM: The cell adhesion molecule L1 is developmentally regulated in the renal epithelium and is involved in kidney branching morphogenesis. J Cell Biol 1998, 143:2067-2079.

12. Thor G, Probstmeier R, Schachner M: Characterization of the cell adhesion molecules L1, N-CAM and $\mathrm{J} 1$ in the mouse intestine. EMBO J 1987 6:2581-2586.

13. Ebeling O, Duczmal A, Aigner S, Geiger C, Schollhammer S, Kemshead JT, Moller P, Schwartz-Albiez R, Altevogt P: L1 adhesion molecule on human lymphocytes and monocytes: expression and involvement in binding to alpha v beta 3 integrin. Eur J Immunol 1996, 26:2508-2516.

14. Kajiwara $Y$, Ueno $H$, Hashiguchi $Y$, Shinto $E$, Shimazaki $H$, Mochizuki H, Hase K: Expression of I1 cell adhesion molecule and morphologic features at the invasive front of colorectal cancer. Am J Clin Pathol 2011, 136:138-144.

15. Doberstein K, Pfeilschifter J, Gutwein P: The transcription factor PAX2 regulates ADAM10 expression in renal cell carcinoma. Carcinogenesis 2011, 32:1713-1723.

16. Bondong S, Kiefel H, Hielscher T, Zeimet AG, Zeillinger R, Pils D, Schuster E, Castillo-Tong DC, Cadron I, Vergote I, et al: Prognostic significance of L1CAM in ovarian cancer and its role in constitutive NF-kappaB activation. Ann Oncol 2012, 23:1795-1802.

17. Kim KS, Min JK, Liang ZL, Lee K, Lee JU, Bae KH, Lee MH, Lee SE, Ryu MJ, Kim SJ, et al: Aberrant I1 cell adhesion molecule affects tumor behavior and chemosensitivity in anaplastic thyroid carcinoma. Clin Cancer Res 2012, 18:3071-3078. 
18. Izumoto S, Ohnishi T, Arita N, Hiraga S, Taki T, Hayakawa T: Gene expression of neural cell adhesion molecule L1 in malignant gliomas and biological significance of L1 in glioma invasion. Cancer Res 1996, 56:1440-1444.

19. Hoefnagel CA, Rutgers M, Buitenhuis CK, Smets LA, de Kraker J, Meli M, Carrel F, Amstutz H, Schubiger PA, Novak-Hofer I: A comparison of targeting of neuroblastoma with mIBG and anti L1-CAM antibody mAb chCE7: therapeutic efficacy in a neuroblastoma xenograft model and imaging of neuroblastoma patients. Eur J Nucl Med 2001, 28:359-368.

20. Thies A, Schachner M, Moll I, Berger J, Schulze HJ, Brunner G, Schumacher $\mathrm{U}$ : Overexpression of the cell adhesion molecule $\mathrm{L} 1$ is associated with metastasis in cutaneous malignant melanoma. Eur J Cancer 2002, 38:1708-1716.

21. Haspel J, Grumet M: The L1CAM extracellular region: a multi-domain protein with modular and cooperative binding modes. Front Biosci 2003 8:s1210-s1225

22. Voura EB, Ramjeesingh RA, Montgomery AM, Siu CH: Involvement of integrin alpha(v)beta(3) and cell adhesion molecule L1 in transendothelial migration of melanoma cells. Mol Biol Cell 2001, 12:2699-2710.

23. Duczmal A, Schollhammer S, Katich S, Ebeling O, Schwartz-Albiez R, Altevogt P: The L1 adhesion molecule supports alpha $v$ beta 3-mediated migration of human tumor cells and activated T lymphocytes. Biochem Biophys Res Commun 1997, 232:236-239.

24. Gavert N, Vivanti A, Hazin J, Brabletz T, Ben-Ze'ev A: L1-mediated colon cancer cell metastasis does not require changes in EMT and cancer stem cell markers. Mol Cancer Res 2011, 9:14-24.

25. Min JK, Kim JM, Li S, Lee JW, Yoon H, Ryu CJ, Jeon SH, Lee JH, Kim JY, Yoon $H K$, et al: L1 cell adhesion molecule is a novel therapeutic target in intrahepatic cholangiocarcinoma. Clin Cancer Res 2010, 16:3571-3580.

26. Jung J, Son YS, Park H, Jeon SK, Lee JW, Choi SY, Kim JM, Kwon YG, Hong HJ, Min JK: The cell adhesion molecule L1 promotes gallbladder carcinoma progression in vitro and in vivo. Oncol Rep 2011, 25:945-952

27. Kodera $Y$, Nakanishi H, Ito S, Misawa K, Ito Y, Nakayama G, Koike M, Fujiwara M, Yamamura Y, Nakao A: Expression of $L 1$ cell adhesion molecule is a significant prognostic factor in pT3-stage gastric cancer. Anticancer Res 2009, 29:4033-4039.

28. Datta SR, Brunet A, Greenberg ME: Cellular survival: a play in three Akts. Genes Dev 1999, 13:2905-2927.

29. Scheid MP, Woodgett JR: PKB/AKT: functional insights from genetic models. Nat Rev Mol Cell Biol 2001, 2:760-768.

30. Manning BD, Cantley LC: AKT/PKB signaling: navigating downstream. Cell 2007, 129:1261-1274

31. Fogel M, Gutwein $P$, Mechtersheimer $S$, Riedle $S$, Stoeck A, Smirnov A, Edler L, Ben-Arie A, Huszar M, Altevogt P: L1 expression as a predictor of progression and survival in patients with uterine and ovarian carcinomas. Lancet 2003, 362:869-875.

32. Fogel M, Mechtersheimer S, Huszar M, Smirnov A, Abu-Dahi A, Tilgen W, Reichrath J, Georg T, Altevogt P, Gutwein P: L1 adhesion molecule (CD 171) in development and progression of human malignant melanoma. Cancer Lett 2003, 189:237-247.

33. Ohnishi T, Matsumura H, Izumoto S, Hiraga S, Hayakawa T: A novel model of glioma cell invasion using organotypic brain slice culture. Cancer Res 1998, 58:2935-2940.

34. Boo YJ, Park JM, Kim J, Chae YS, Min BW, Um JW, Moon HY: L1 expression as a marker for poor prognosis, tumor progression, and short survival in patients with colorectal cancer. Ann Surg Oncol 2007, 14:1703-1711.

35. Kaifi JT, Reichelt U, Quaas A, Schurr PG, Wachowiak R, Yekebas EF, Strate T, Schneider C, Pantel K, Schachner M, et al: L1 is associated with micrometastatic spread and poor outcome in colorectal cancer. Mod Pathol 2007, 20:1183-1190.

36. Gavert N, Conacci-Sorrell M, Gast D, Schneider A, Altevogt P, Brabletz T, Ben-Ze'ev A: L1, a novel target of beta-catenin signaling, transforms cells and is expressed at the invasive front of colon cancers. J Cell Biol 2005, 168:633-642.

37. Siesser PF, Maness PF: L1 cell adhesion molecules as regulators of tumor cell invasiveness. Cell Adh Migr 2009, 3:275-277.

38. Panicker AK, Buhusi M, Erickson A, Maness PF: Endocytosis of beta1 integrins is an early event in migration promoted by the cell adhesion molecule L1. Exp Cell Res 2006, 312:299-307.
39. Yang M, Li Y, Chilukuri K, Brady OA, Boulos MI, Kappes JC, Galileo DS: L1 stimulation of human glioma cell motility correlates with FAK activation. J Neurooncol 2011, 105:27-44

40. Kiefel $\mathrm{H}$, Bondong S, Pfeifer M, Schirmer U, Erbe-Hoffmann N, Schafer $\mathrm{H}_{\text {, }}$ Sebens S, Altevogt P: EMT-associated up-regulation of L1CAM provides insights into L1CAM-mediated integrin signalling and NF-kappaB activation. Carcinogenesis 2012, 33:1919-1929.

41. Kiefel $H$, Bondong S, Erbe-Hoffmann N, Hazin J, Riedle S, Wolf J, Pfeifer M, Arlt A, Schafer H, Muerkoster SS, Altevogt P: L1CAM-integrin interaction induces constitutive NF-kappaB activation in pancreatic adenocarcinoma cells by enhancing IL-1beta expression. Oncogene 2010, 29:4766-4778.

42. Bao S, Wu Q, Li Z, Sathornsumetee S, Wang H, McLendon RE, Hjelmeland AB, Rich JN: Targeting cancer stem cells through L1CAM suppresses glioma growth. Cancer Res 2008, 68:6043-6048.

43. Gast D, Riedle S, Issa Y, Pfeifer M, Beckhove P, Sanderson MP, Arlt M, Moldenhauer G, Fogel M, Kruger A, Altevogt P: The cytoplasmic part of L1-CAM controls growth and gene expression in human tumors that is reversed by therapeutic antibodies. Oncogene 2008, 27:1281-1289.

44. Arlt MJ, Novak-Hofer I, Gast D, Gschwend V, Moldenhauer G, Grunberg J, Honer M, Schubiger PA, Altevogt P, Kruger A: Efficient inhibition of intra-peritoneal tumor growth and dissemination of human ovarian carcinoma cells in nude mice by anti-L1-cell adhesion molecule monoclonal antibody treatment. Cancer Res 2006, 66:936-943.

45. Knogler K, Grunberg J, Zimmermann K, Cohrs S, Honer M, Ametamey S, Altevogt P, Fogel M, Schubiger PA, Novak-Hofer I: Copper-67 radioimmunotherapy and growth inhibition by anti-L1-cell adhesion molecule monoclonal antibodies in a therapy model of ovarian cancer metastasis. Clin Cancer Res 2007, 13:603-611.

46. Sebens Muerkoster S, Werbing V, Sipos B, Debus MA, Witt M, Grossmann M, Leisner D, Kotteritzsch J, Kappes H, Kloppel G, et al: Drug-induced expression of the cellular adhesion molecule L1CAM confers anti-apoptotic protection and chemoresistance in pancreatic ductal adenocarcinoma cells. Oncogene 2007, 26:2759-2768.

47. Schafer H, Dieckmann C, Korniienko O, Moldenhauer G, Kiefel H, Salnikov A, Kruger A, Altevogt P, Sebens S: Combined treatment of L1CAM antibodies and cytostatic drugs improve the therapeutic response of pancreatic and ovarian carcinoma. Cancer Lett 2012, 319:66-82.

48. Silletti S, Yebra M, Perez B, Cirulli V, McMahon M, Montgomery AM: Extracellular signal-regulated kinase (ERK)-dependent gene expression contributes to L1 cell adhesion molecule-dependent motility and invasion. J Biol Chem 2004, 279:28880-28888.

49. Stoeck A, Gast D, Sanderson MP, Issa Y, Gutwein P, Altevogt P: L1-CAM in a membrane-bound or soluble form augments protection from apoptosis in ovarian carcinoma cells. Gynecol Oncol 2007, 104:461-469.

50. Yoon H, Min JK, Lee DG, Kim DG, Koh SS, Hong HJ: L1 cell adhesion molecule and epidermal growth factor receptor activation confer cisplatin resistance in intrahepatic cholangiocarcinoma cells. Cancer Lett 2012, 316:70-76.

51. Zeng ZL, Wu WJ, Yang J, Tang ZJ, Chen DL, Qiu MZ, Luo HY, Wang ZQ, Jin $Y$, Wang DS, Xu RH: Prognostic relevance of melanoma antigen D1 expression in colorectal carcinoma. J Trans/ Med 2012, 10:181.

52. Zou J, Li P, Lu F, Liu N, Dai J, Ye J, Qu X, Sun X, Ma D, Park J, Ji C: Notch1 is required for hypoxia-induced proliferation, invasion and chemoresistance of T-cell acute lymphoblastic leukemia cells. J Hematol Oncol 2013, 6:3.

53. Wu ZL, Song YQ, Shi YF, Zhu J: High nuclear expression of STAT3 is associated with unfavorable prognosis in diffuse large B-cell lymphoma. J Hematol Oncol 2011, 4:31.

54. Lee SB, Schramme A, Doberstein K, Dummer R, Abdel-Bakky MS, Keller S, Altevogt $P$, Oh ST, Reichrath J, Oxmann D, et al: ADAM10 is upregulated in melanoma metastasis compared with primary melanoma. $J$ Invest Dermatol 2010, 130:763-773.

55. Huang S, Jean D, Luca M, Tainsky MA, Bar-Eli M: Loss of AP-2 results in downregulation of $\mathrm{c}-\mathrm{KIT}$ and enhancement of melanoma tumorigenicity and metastasis. EMBO J 1998, 17:4358-4369.

doi:10.1186/1756-8722-6-43

Cite this article as: Chen et al:: L1cam promotes tumor progression and metastasis and is an independent unfavorable prognostic factor in gastric cancer. Journal of Hematology \& Oncology 2013 6:43. 